\title{
Escutando o outro: aproximações e distanciamentos nas histórias de vida e na clínica
}

\author{
Maria Lívia de Sá RORIZ ${ }^{1}$
}

\begin{abstract}
Resumo:
$\mathrm{O}$ artigo aborda aspectos inerentes às técnicas empregadas em pesquisas de comunicação, quando utilizam-se de entrevistas baseadas em histórias de vida, comparando esta abordagem de escuta com a realizada na clínica analítica. O objetivo da investigação é mostrar aproximações e distanciamentos entre as duas técnicas, destacando como, a partir do ato de ouvir o outro, alguns aspectos empregados na clínica poderiam ser incorporados às entrevistas realizadas na área da comunicação que, a partir dos pressupostos da história oral, usam histórias de vida como base empírica-metodológica.
\end{abstract}

Palavras-chave: Histórias de vida. Entrevista. Comunicação. Psicologia. Método.

\section{Listening to the other: approaches and distances in life stories and in the clinic}

\begin{abstract}
:
This paper deals with aspects related to the techniques used in communication research, when interviews based on life stories are used, comparing this listening approach with that used in the analytical clinic. The objective of the research is to show approaches and distances between the two techniques, highlighting how some aspects used in the clinic could be incorporated into the interviews carried out in the area of communication, starting from the premises of oral history whose empirical-methodological basis is the life story.
\end{abstract}

Keywords: Storytelling. Interview. Communication. Psychology. Method.

\section{Escuchar al otro: enfoques y distancias en las historias de vida y en la clínica}

\begin{abstract}
:
El artículo discute aspectos inherentes a las técnicas utilizadas en la investigación en comunicación, al utilizar entrevistas basadas en historias de vida, comparando este enfoque de escucha con el realizado en la clínica analítica. El objetivo de la investigación es mostrar aproximaciones y distancias entre las dos técnicas, destacando cómo, desde el acto de escuchar al otro, algunos aspectos utilizados en la clínica podrían incorporarse a las entrevistas realizadas en el área de la comunicación que, a partir de los supuestos de la historia oral, utilizar historias de vida como base empírico-metodológica.
\end{abstract}

Keywords: Historias de vida. Entrevistas. Comunicación. Psicología. Método.

\footnotetext{
${ }^{1}$ Pós-Doutoranda em Comunicação no Programa de Pós-Graduação em Comunicação e Cultura da Universidade Federal do Rio de Janeiro. Bolsista PNPD-CAPES. Doutora em Comunicação e Cultura pelo Programa de PósGraduação em Comunicação e Cultura (PPGCOM) da UFRJ. Mestre em Psicologia Social pelo Programa de Pós-Graduação em Psicologia Social pela Universidade do Estado do Rio de Janeiro (UERJ). Graduação em Psicologia pela Universidade Gama Filho (UGF).E-mail: marialiviaroriz@gmail.com
} 


\section{Introdução}

"Por obséquio, conte-me o que sabe a respeito de si próprio" (FREUD, 1913, p. 83).

A epígrafe retirada do texto de Freud denominado "Recomendações aos médicos que exercem a psicanálise" foi propositalmente escolhida para abrir este texto, pois, no nosso entendimento, se constitui numa espécie de síntese tanto das entrevistas de histórias de vida, que muitas vezes tomam como pressuposto a teoria/metodologia da história oral, como daquelas que são realizadas na clínica analítica. Nas duas situações, é o trabalho de memória do entrevistado que fornece material indispensável para contar novamente sua história. Em ambos os casos, o ato declaratório de si mesmo abre possibilidades infinitas tanto para o pesquisador quanto para o analista.

Assim, o objetivo deste artigo é produzir algumas reflexões sobre o que podemos chamar a escuta do outro em duas situações: nas entrevistas realizadas com o objetivo de conhecer histórias de vida, usadas frequentemente em pesquisas da área de Comunicação, e as entrevistas que se efetuam a partir das técnicas da clínica psicológica. O objetivo da investigação é compreender quais são as aproximações, distanciamentos e confluências entre essas práticas.

A nosso ver, o presente texto produz uma série de observações que pode ser útil às pesquisas em Comunicação se considerarem, na utilização metodológica e empírica da escuta de histórias de vida, quais as similitudes e diferenças entre os pressupostos dos dois tipos de abordagem para a escuta do entrevistado.

Para isso, partimos de um duplo lugar: o de psicóloga, com décadas de prática em clínica, e o de pesquisadora de Comunicação, que utilizou, ao longo do percurso acadêmico, as histórias de vida como possibilidade de análise empírica (RORIZ, 2013, 2018).

Portanto, cabem algumas considerações sobre a questão das histórias de vida como possibilidade de construir uma arquitetura metodológica em torno das entrevistas. Utilizadas, sobretudo, a partir dos pressupostos teóricos e metodológicos da história oral, as histórias de vida se mostram como possibilidades de reconstruir caminhos na busca de uma interpretação. A entrevista transforma-se em diálogo comunicacional que revela subjetividades e estabelece elos entre entrevistado e entrevistador.

Nas histórias de vida, é a ação viva da memória que produz os dados empíricos fundamentais para a interpretação. O historiador Portelli (1997) define história oral como uma arte, uma reconstrução da vida por intermédio da narrativa, o processo de escutar vozes de 
pessoas comuns, de dar voz aos que, em princípio, não a teriam. É uma metodologia centrada no movimento de ouvir o outro, permitindo conhecer a trajetória de atores envolvidos.

Assim, a história oral não deve ser considerada apenas um método, mas é, sobretudo, uma dimensão teórica cujos parâmetros devem ser observados também na dimensão técnica da metodologia. Agrega modos de fazer e de teoria, sendo um método, uma interpretação e uma teoria em relação a determinado objeto de pesquisa (AMADO; FERREIRA, 2006).

A entrevista é um diálogo comunicacional, pois é o resultado do encontro possibilitado pela pesquisa de campo. O que ganha relevo são os conteúdos da memória, evocados e organizados numa troca viva e ativa entre entrevistado e entrevistador (PORTELLI, 2010). Portanto, a questão da memória estará sempre presente e interpelando aquele que faz das histórias de vida - temáticas ou não - ferramentas indispensáveis para a pesquisa.

Ainda que não seja o foco central do artigo, no decorrer do texto aproximaremos reflexões de caráter mais teórico da prática de pesquisa, utilizando pontualmente exemplos de entrevistas realizadas com sambistas idosos do Rio de Janeiro. Procuramos mostrar não apenas a técnica utilizada, mas também refletir sobre como a forma como é realizada a entrevista induz a pensar numa memória produzida em fluxo, num presente que interpela sem cessar um passado que se cristaliza em jogos emocionais de lembranças. A relação entre tempos, fundamental para a compreensão da historicidade dos processos comunicacionais, ganha dimensão ao ser acionada a partir de um fluxo contínuo de lembranças, numa entrevista que procura também não conhecer previamente as histórias de vida dos entrevistados.

\section{Da clínica às histórias de vida}

Diante da opção de Freud de publicar somente no fim de sua vida, em 1937, seu texto de 1913, cuja frase serve como epígrafe para o artigo, poderíamos questionar e chegar a variadas conclusões sobre a relutância de Freud em apresentar metodologicamente a forma de atuação do analista/terapeuta. São os fatores psicológicos envolvidos nos tratamentos principalmente que levaram a tamanha hesitação nos escritos freudianos. Discorrer sobre a técnica é revelar métodos, escutas e interpretações de conteúdos subjetivos, íntimos e, desse modo, seria revelar-se.

Segundo Freud (1931/1937), o domínio não vem da teoria e, sim, da técnica, sendo, então, a prática analítica essencial para o aperfeiçoamento do profissional. $\mathrm{O}$ autor destaca como fundamentais os processos subjetivos de cada um envolvido no procedimento 
(entrevistador e entrevistado):

\begin{abstract}
Devo, contudo, tornar claro que o que estou asseverando é que esta técnica é a única apropriada à minha individualidade; não me arrisco a dizer e a negar que um médico constituído de modo inteiramente diferente possa ver-se levado a adotar atitude diferente em relação a seus pacientes e à tarefa que se lhe apresenta (FREUD, 1913/1969, p. $67^{2}$ ).
\end{abstract}

Freud afirma, portanto, a importância da individualidade e dos elementos compreendidos no processo, ou seja, as vivências, os espaços habitados, as culturas experimentadas. Trabalhar com conteúdo analítico não conduz somente a uma incursão no mundo subjetivo alheio, mas à imersão em conteúdos subjetivos (emoções, traumas, patologias) e a outros que poderíamos classificar como objetivos (cultura, território, etc.). Lidar com a subjetividade do outro é ir ao encontro de histórias de vida imersas em cada ser, como se fôssemos chamados a uma excursão em vidas alheias. Ao mesmo tempo, compreendemos, com a transferência, a atuar em conteúdos inconscientes e subjetivos do analista.

Uma questão se coloca ao analista: ao descortinar os conteúdos, ao compreender a história de vida de cada paciente, não estaríamos fazendo parte dessa história? O que diferencia a nossa posição? Será que o analista não é alguém que, ao evocar lembranças encobertas, descortina suas próprias lembranças? Nesse sentido, Freud (1913/1969, p. 68) claramente orienta: "não se deve esquecer que o que se escuta, na maioria, são coisas cujo significado só é identificado posteriormente".

A técnica da análise consiste na escuta do terapeuta, ato que parece simples, mas que no cotidiano da profissão compreendemos ser uma engrenagem de ações.

\begin{abstract}
A técnica, contudo, é muito simples. Como se verá, ela rejeita o emprego de qualquer expediente especial (mesmo de tomar notas). Consiste simplesmente em não dirigir o reparo para algo específico e em manter a mesma 'atenção uniformemente suspensa' (como a denominei) em face a tudo o que se escuta (FREUD, 1913/ 1969, p. 67).
\end{abstract}

Ao escutar a história de vida do paciente, o analista/terapeuta deve usar sua escuta sem se preocupar com o que retém de conteúdo. Segundo Freud, no momento da entrevista não

\footnotetext{
${ }^{2}$ Originalmente, o texto de Freud foi dividido em duas partes publicadas respectivamente em janeiro e março de 1913. Cf. nota do editor inglês em "Sobre o início do tratamento (novas recomendações sobre a técnica da Psicanálise)", 1969, p, 75.
} 
devemos anotar, gravar, usar outro recurso que não seja a nossa percepção, memória e atenção, utilizando somente daquilo que perpassa nossos sentidos: a audição, a visão, o tato, o olfato. O conteúdo de uma sessão não é somente dialógico e analítico; dentro da narrativa existem também os olhares, as ações, bem como a morbidez, os engessamentos. O que adentra essa escuta não é somente o que é dito, mas também o que transpassa pela narrativa, em conteúdos subjetivos ou objetivos, as lembranças encobridoras, resistências, transferências, entre outros.

Durante todo o tratamento, um movimento de ação mnemônica do terapeuta será acionado, já que, no ato de "repetir, recordar e elaborar"3, são realizadas as elaborações dos fatos. Freud orienta que o profissional permita que essa memória seja acionada e que as associações ocorram de acordo com as memórias que vão se descortinando. Não se faz necessário reter todo o conteúdo das sessões e é por esse motivo que despreza o uso de anotações na presença do paciente. O que o terapeuta faz é acionar essas memórias a partir dos conteúdos que aparecem em cada sessão.

Assim, para explorar as primeiras aproximações e distanciamentos de metodologia das duas práticas, podemos perguntar: o que diferencia o movimento mnemônico ocorrido nas sessões terapêuticas com a entrevista da metodologia da história de vida? Quais são os pontos em que se cruzam e em quais divergem?

Se na clínica Freud desaconselha as anotações na presença do paciente, ao se realizar uma entrevista, nas histórias de vida é obrigatório reter a narrativa para, a partir do testemunho, compreender os caminhos do entrevistado que se constituirão em dados empíricos da pesquisa. Diferente do processo analítico que demandará encontros semanais, em geral, uma entrevista com personagens escolhidos pelo próprio pesquisador, visando à captação de uma memória para reconstruir uma história de vida relacionada a uma temática central, é realizada em um único encontro. Isso requer outro tempo cronológico que, na entrevista, muitas vezes é maior do que uma sessão de cinquenta minutos.

Quando um paciente entra num consultório, a rigor, não conhecemos a sua história, da qual muitas vezes ele próprio não possui domínio, sendo o processo clínico o que permite o conhecimento e a elaboração da sua própria história de vida. Assim, a depender do caso, são dezenas, até centenas de encontros.

Já numa entrevista de histórias de vida temos que conhecer, muitas vezes num único encontro, aspectos relevantes da história pessoal do entrevistado, que serão fundamentais para

\footnotetext{
${ }^{3}$ A expressão foi usada entre aspas, pois é uma referência explicita ao texto de Freud (1914), com o mesmo nome.
} 
a pesquisa. Para que nenhum fragmento narrativo se perca, o uso do gravador faz-se necessário, embora muitas vezes se constitua como espécie de mecanismo impeditivo, já que inibe o entrevistado. Além disso, a gravação dificulta a produção de associações livres. Diferente das sessões terapêuticas que fluem no decorrer do processo analítico, as entrevistas de produção de histórias de vida se tornam momentos únicos de acionar as memórias.

Ao instruir sobre as formas de atuação na clínica e sobre os usos da escuta - tanto do paciente quanto do analista - Freud apresenta a questão dialógica também presente quando refletimos sobre as processualidades comunicacionais. Uma sessão de análise é construída a partir de ondas de recepção entre os conteúdos inconscientes de paciente e analista. E os trabalhos da memória são atos comunicacionais.

Assim, como o paciente deve relatar tudo o que sua auto-observação pode detectar, e impedir todas as objeções lógicas e afetivas que procuram induzilo a fazer uma seleção dentre elas, também o médico deve colocar-se em posição de fazer uso de tudo o que lhe é dito para fins de interpretação e identificar o material inconsciente oculto, sem substituir sua própria censura pela seleção de que o paciente abriu mão.

Nesses trabalhos estão envolvidas diversas ações: os silenciamentos, as revelações, os encobrimentos, as elaborações e os múltiplos esquecimentos. Em uma bela metáfora, Freud coloca o analista como uma espécie de "receptor telefônico", comparando explicitamente suas ações aos processos tecnológicos comunicacionais mais inovadores do seu tempo.

Para melhor formulá-lo: ele deve voltar seu próprio inconsciente, como um órgão receptor, a direção do inconsciente transmissor do paciente. Deve ajustar-se ao paciente como um receptor telefônico se ajusta ao microfone transmissor. Assim, como o receptor transforma de novo em ondas sonoras as oscilações elétricas na linha telefônica, que foram criadas por ondas sonoras, da mesma maneira o inconsciente do médico é capaz, a partir dos derivados do inconsciente que lhe são comunicados, de reconstruir esse inconsciente, que determinou as associações livres do paciente (FREUD, 1913/1969, p. 70).

Ao instruir sobre o início do tratamento de pacientes sobre os quais não temos conhecimento prévio, Freud indica que se deve deixar, em uma ou duas sessões, a pessoa falar livremente, sem interrupções ou qualquer análise sobre o conteúdo. Somente elaboramos com pacientes que sabemos que darão continuidade ao tratamento e após a transferência. Se 
compararmos essa prática com a escuta produzida nas entrevistas de história oral, executamos a mesma técnica. O tempo da escuta é livre, sem interrupções, e é a própria pessoa que narra o que tem de domínio sobre suas lembranças. É aconselhável nenhuma interferência, porém, muitas vezes, a intervenção ocorre, ainda que pontualmente. Há, por meio de uma palavra ou gesto, a procura por algum esquecimento do entrevistado.

Mas posso acrescentar que desde então tornei um hábito meu, quando conheço pouco sobre um paciente, só aceitá-lo a princípio provisoriamente, por um período de uma ou duas semanas. Se se interrompe o tratamento dentro deste período, poupa-se ao paciente a impressão aflitiva de uma tentativa de cura que falhou. Esteve-se apenas empreendendo uma 'sondagem', a fim de conhecer o caso e decidir se ele é apropriado a psicanálise. [...] Este experimento preliminar, contudo, é ele próprio, o início de uma psicanálise e deve conformar-se às regras desta (FREUD, 1913/1969, p. 76).

Freud, ao explicar o uso do divã e da posição que adotava - a de sempre se colocar posicionado atrás do paciente - defende a necessidade de o analista não revelar seus "pensamentos inconscientes" que se deixam ver em atos e expressões corporais. Dizia: "visto que, enquanto estou escutando um paciente, também me entrego à corrente de meus pensamentos inconscientes; não desejo que minhas expressões faciais deem ao paciente material para interpretação ou influenciem-no no que me conta" (FREUD, 1913/1969, p. 83).

Se a escuta analítica surge condensada em "pensamentos inconscientes", durante a realização das entrevistas da história oral também há o atravessamento de conteúdos pessoais. O que acontece desde a escolha do tema da pesquisa, até a seleção dos entrevistados. A temática refere-se aos nossos interesses pessoais, as nossas histórias de vida e, sendo assim, os entrevistados sempre irão produzir conteúdos em suas falas que habitam nossos pensamentos inconscientes.

Além disso, nas entrevistas também se torna necessário distinguir a transferência e a contratransferência. A escuta que se produz pode incluir pensamentos inconscientes, mas ainda assim são os conteúdos constituintes da fala do outro, de sua história, de seus atos de “repetir, recordar e elaborar". É uma escuta atenta à história do outro, compreendendo, contudo, que nesse processo pode ocorrer aproximações com a própria história de vida do entrevistador. 
No processo analítico, a pessoa é livre para começar a relatar a sua história, não há uma condução da ordem com que os conteúdos vão aparecer.

O material com que se inicia o tratamento é, em geral, indiferente - a história da vida do paciente, ou a história de sua doença, ou suas lembranças de infância. Mas, em todos os casos, deve-se deixar que o paciente fale e ele deve ser livre para escolher em que ponto começará. Dessa maneira, dizemos-lhe: 'Antes que eu possa dizer algo, tenho de saber muita coisa sobre você; por obséquio, conte-me o que sabe a respeito de si próprio' (FREUD, 1913/1969, p. 83).

Essa reflexão freudiana, embora se refira à prática analítica, pode servir como argumento central também para a condução das entrevistas que usam como metodologia a história de vida. Em princípio, o que estamos querendo saber são os caminhos daquelas vidas, o que cada um pode revelar de si.

Assim como no início do tratamento é necessário que se deixe o paciente livre para falar, produzir "associações livres" sem a condução do analista e a partir da organização de seus trabalhos de memória, essa mesma condução poderia ser adotada nas entrevistas da metodologia das histórias de vida, já que buscamos testemunhos de uma vida vivida, numa trajetória múltipla, que necessariamente não começa no seu nascimento. ${ }^{4}$

$\mathrm{Na}$ entrevista clínica, há a garantia para o paciente que ali é um espaço de liberdade para o pensamento: não haverá julgamentos, não haverá revelações e publicizações. Freud, mais uma vez utilizando de imagens metafóricas que permitem múltiplas associações imaginativas, sintetiza efetivamente esse processo.

Assim, diga tudo o que lhe passa pela mente. Aja como se, por exemplo, você fosse um viajante sentado à janela de um vagão ferroviário, a descrever para alguém que se encontra dentro as vistas cambiantes que vê lá fora. Finalmente, jamais esqueça que prometeu ser absolutamente honesto e nunca deixar nada de fora porque, por uma razão ou outra, é desagradável dizê-lo (FREUD,1913/1969, p. 84).

\footnotetext{
${ }^{4}$ Na metodologia das histórias de vida, para a história oral, há a recomendação de que se produza uma espécie de abertura e apaziguamento da memória do entrevistado, pedindo a este que comece falando da sua mais recôndita história, ou seja, localizando suas lembranças num momento chave, cronológico, isto é, onde tudo começou, ponto que normalmente remete às vidas dos pais e o momento de nascimento.
} 
$\mathrm{Na}$ proposta de entrevista com a metodologia da história oral, não assinalamos que os conteúdos podem ser livres de julgamentos, pois, de fato, vão se transformar em documentos públicos e, assim, vetor de repressão. Além de a narrativa ser transformada em documento, existem os acessórios que podem se tornar inibidores: um simples gravador, uma máquina fotográfica ou uma filmadora. No decorrer das entrevistas, com frequência, pode ser pedido para que o pesquisador desligue o gravador, não transcreva alguma informação, cujo conteúdo só surgiu porque se criou uma vinculação entre entrevistado e entrevistador. Frases como “isso está sendo gravado?”, "vou contar, mas não relate”, “direi isso para que você possa entender a história" aparecem nas entrevistas como formas de controle daquilo que escapa. São tramas narrativas que só aparecem nas histórias contadas por uma confiança na pessoa que entrevista. Diferente do tratamento analítico em que o terapeuta acorda que os conteúdos serão mantidos em segredo, na entrevista de história oral esse é um juramento que não pode imperar. Os conteúdos produzidos são importantes, fundamentais para compreender o objeto empírico da pesquisa e, consequentemente, serão revelados.

Embora haja essas distinções fundamentais, há que se remarcar que as duas narrativas, tanto a da clínica quanto a da pesquisa testemunhal, se transformam em conhecimento: na análise são produzidos conhecimentos de si, da sua própria história de vida, enquanto, mesmo se observando movimento similar na entrevista de história oral, o conhecimento produzido tomará a cena pública ao se transformar em documento, que poderá ser acionado inúmeras vezes para que se produza análises de outras vidas entrelaçadas à história de vida daquele que depõe.

Cabe ressaltar também que a conquista da confiança do outro pode não se dar em apenas um encontro. Essa ação paulatina obrigaria, como recomendação às entrevistas de histórias de vida, que essas também fossem realizadas em diversos encontros, indispensáveis para o conhecimento mútuo do outro e para o estabelecimento de laços fundamentais à abertura da memória em direção a trabalhos que revelam vidas, emoções, sentimentos.

Por fim, é preciso compreender que o ato de entrevistar não é somente de escuta. Nele, estão contidos vários outros elementos. O ponto nodal é a fala, mas, a partir dela, se relacionam outros elementos constitutivos: o lugar onde se realiza a entrevista; a maneira como o entrevistado se veste para ir ao encontro do pesquisador; as pessoas que, eventualmente, acompanham a entrevista (já que, muitas vezes, não conseguimos realizá-las apenas com o entrevistado); suas expressões e seus gestos. A fala é parte constitutiva de um 
conjunto que representa a história a ser contada.

Quanto ao tempo de escuta dessa narrativa, Freud indica que na análise os pormenores se repetem, o que não é o caso da entrevista da história oral. Assim, nesta última, o entrevistador deve ficar mais atento aos pormenores (já que se sabe de antemão que, provavelmente, não haverá outro encontro) não apenas da fala, mas de todos os outros sentidos (a visão, o olfato, o tato e até o paladar). Exige-se do entrevistador uma atenção integral.

Neste item destacamos as aproximações e diferenças da técnica das entrevistas das histórias de vida e as escutas realizadas na clínica analítica, procurando enfatizar como alguns pressupostos da técnica analítica poderiam aprofundar as entrevistas de histórias de vida, aprimorando a metodologia utilizada.

\section{Gestão da memória}

Se pudéssemos atribuir um papel de personagem central nas técnicas analisadas nesse artigo, certamente, a memória ${ }^{5}$ ocuparia esse lugar. Entretanto, apesar de sua centralidade nos dois casos, podemos dizer que, na clínica, seu acionamento se dá de maneira processual, o que demanda, normalmente, um tempo maior. Na história oral, esse acionamento tem que ser mais ágil e é determinado por um objetivo pontual.

Para Freud, rememorar é um ato que se constrói na ação consciente e inconsciente, em emoções que transbordam a partir de ações. A memória que lidamos é sempre coletiva. Ainda que seja acionada por um único indivíduo, está incluída nos diversos grupos dos quais o sujeito participa. O fenômeno memorável, como remarca Pollak (1992, p. 201), é “construído coletivamente e submetido a flutuações, transformações, mudanças constantes”.

Os conteúdos que emergem nas entrevistas são sempre acionados no presente, já que são elaborados a partir de uma narrativa atual. É o ato de narrar que reativa eventos do passado. Essas lembranças vividas podem vir carregadas de sentimentos que, no caso do processo analítico, por ter o tempo a seu favor, são expressas de maneira contínua num período mais longo. No caso das entrevistas de histórias de vida, não há tempo longo, nem a perspectiva de continuidade. Assim, há quase a emergência de acionamento das memórias do entrevistado que dizem respeito ao tema abordado. Na entrevista clínica se tem o cuidado de não deixar os conteúdos intensos transbordarem rapidamente, enquanto na entrevista da

\footnotetext{
${ }^{5}$ São inúmeras as reflexões e questões envolvidas na problemática da memória nas Ciências Humanas (cf., entre outros, NORA, 1984; HALBWACHS, 2006; HUYSSEN, 2000; RICOEUR, 2008; CANDAU, 2011). Neste artigo utilizaremos, sobretudo, as reflexões de Pollak (1989; 1992), por tratarem de pontos importantes na condução das argumentações, isto é, a questão do silêncio, das identidades e das memórias traumáticas.
} 
história oral, comumente, o transbordamento dos conteúdos é fundamental para a própria pesquisa.

Outro aspecto que correlaciona, mais uma vez, a memória com a questão temporal diz respeito aos diferentes objetivos do entrevistado na clínica e na produção do documento oral de pesquisa. No primeiro caso, geralmente, interessa ao paciente o tempo presente e trabalhar suas angústias da vida vivida agora, havendo, muitas vezes, um esquecimento deliberado do passado (que só muito lentamente vai se enunciando). Já no segundo caso, são as lembranças do passado que devem imperar. Sem elas, não se formará o documento de pesquisa.

Na história oral, durante a transferência da memória pode haver a eclosão de uma memória herança, de fatos vividos, por exemplo, pelos ascendentes e que na narrativa são construídos como se fossem testemunhados pelo depoente. Os entrevistados se apropriam de fatos, imagens, descrições vividas por seus pais, familiares e pessoas próximas e, com isto, constroem sua própria história: a narrativa familiar e do grupo aparecem como sendo parte de sua trajetória individual. Esse processo é particularmente visível nas entrevistas com pessoas mais idosas. Ao realizar pesquisa com integrantes da Velha Guarda das escolas de samba do Rio de Janeiro (RORIZ, 2013), inúmeras vezes esses encadeamentos puderam ser percebidos. É o movimento de fazer parte de histórias, mesmo que não se esteja presente nelas, que constrói um pertencimento ao grupo referenciado a partir de uma cadeia de fatos memoráveis.

Quando se fala em construções da memória, estamos nos referindo aos elementos consciente e inconsciente, aos trabalhos de memória a que Freud tanto se referia como base de operação do aparelho psíquico. Ao dialogar com a teoria freudiana, Pollak (1992, p. 203-204) destaca o fato de que "a memória individual grava, recalca, exclui, relembra" num "verdadeiro trabalho de organização". Portanto, nos dois casos, o que vem à tona são os trabalhos de memória.

Assim, o ato da entrevista se torna para o entrevistado a possibilidade de elaboração de sua vida. Ao narrar sua história, diz em voz alta as ações que constituíram momentos de sua trajetória e é capaz de rever as ações do passado no presente. Ao recontar os atos vividos, abre-se a oportunidade de analisar a própria vida a partir dos relatos. Segundo Pollak (1992), na entrevista da história oral, executamos uma organização da memória, sua seleção entre os elementos inconscientes, conscientes, os recalques, as transferências, sendo sempre o ato de contar a história de sua vida uma ação de elaboração.

Um dos elementos que divergem nas duas entrevistas diz respeito ao preparo do 
profissional para a sua realização. Conforme já dito anteriormente, na história de vida é fundamental que o entrevistador conheça minúcias do entrevistado, prepare um roteiro prédeterminado da entrevista, para que, caso o entrevistado pule tempos e fatos em algum momento, possa, por meio de uma expressão breve, fazê-lo voltar na narrativa de forma que aquele aspecto não se perca. Na clínica, essa possibilidade não existe, já que o que importa é a eclosão dos fluxos da memória, deixando se ver tanto as partes sólidas, como as menos sólidas (POLLAK, 1992).

O analista não conhece a história da pessoa que chega ao consultório. No caso da entrevista de história de vida, o próprio convite já é um preparo, uma vez que somente será escolhido e chamado aquele que poderá acrescentar informações indispensáveis ao contexto da pesquisa.

Produzir uma entrevista, em qualquer situação, é sempre um ato de falar de si. Entretanto, como remarca Pollak (1992, p. 211), quando o entrevistado nas histórias de vida toma consciência de que vai falar da sua existência, há um enorme estranhamento diante da descoberta (sempre como dúvida) de que sua vida importa. A pergunta que emerge certamente é "em que a minha vida importa"? São pessoas comuns, que podem ser qualificados como excluídos da história, normalmente os que não têm voz na sociedade, a quem não é dado o direito de transformar a vida em documento. Já quando o paciente procura uma clínica privada, o pressuposto é que ele está se dirigindo àquele lugar para falar de sua vida, ou seja, para ele, sua vida importa.

Um outro elemento importante presente nas duas entrevistas diz respeito à questão do silêncio. Pollak (1989), ao realizar sua pesquisa sobre os campos de concentração nazistas durante a Segunda Guerra Mundial, se deparou com um silêncio eloquente: o das mulheres que tinham sido violentadas na prisão, que não conseguiam verbalizar o acontecimento. Nesse caso, o abafamento da fala se transformou num silêncio duradouro, lido por Pollak como acontecimento traumático. São lembranças guardadas e que, muitas vezes, estão à espera de uma escuta para serem reveladas. Na clínica, o silêncio é material palpável e analítico, enquanto nas histórias de vida é preciso descortiná-lo e transformá-lo em ditos.

A similitude nos dois tipos de entrevista é discorrer sobre alguma coisa do passado que pode ser algo traumático. Nesse caso, tanto o pesquisador como o analista se transformam naquele que está presente para escutar e trazer à superfície fatos dolorosos. No processo terapêutico os silêncios circulam com mais frequência, enquanto nas entrevistas os silêncios 
precisam abrir espaço na narrativa. Em ambos os casos, o que permite a eclosão do silencio é a escuta.

Assim como o analista, o pesquisador se torna o veículo para a materialização do testemunho e, por meio da escuta, pode absorver histórias e transformá-las em documentos. Entra-se, então, no cotidiano do entrevistado, em seu modo de vida e da vida das pessoas em seu no entorno. Constrói-se uma relação pessoal, se estabelece um vínculo, o que pode se transformar num problema para a coleta e a análise do material. Como aponta Amado (1997), o envolvimento pode prejudicar a própria condução da entrevista. Uma vez guiado pela emoção, o entrevistador pode esquecer momentaneamente o seu papel, criando laços mais profundos com o entrevistado. A autora destaca que essas emoções, ao repercutirem no trabalho final, podem distorcer a própria pesquisa (AMADO, 1997).

Cabe uma breve consideração sobre as implicações éticas presentes em ambas as modalidades de entrevistas. Mesmo que se tenha a consciência do ato ético em qualquer entrevista, nas que abordam as histórias de vidas essa questão é crucial: transformar a vida de pessoas vivas em documentos públicos pode trazer consequências para suas existências. Em função disso, a transcrição das entrevistas pode sofrer alterações, obrigando, por exemplo, a omissão de determinados trechos. Nem sempre o que é dito será divulgado, visando à proteção da pessoa entrevistada.

Convém, por último, sublinhar dois aspectos que se referem mais diretamente às historicidades dos processos comunicacionais presentes nas entrevistas da história oral. $\mathrm{O}$ conhecimento prévio da biografia do entrevistado é tido como fundamental, como destacamos anteriormente. Mas, a partir da prática, realizando dezenas de entrevistas com sambistas para perceber suas inserções no mundo (RORIZ, 2013, 2018), fiz uso exatamente da premissa da clínica analítica e cheguei para as entrevistas sem o conhecimento da vida daqueles personagens. Isso possibilitou menor interferência no desenrolar dos fluxos memoráveis das entrevistas, fazendo emergir um passado mítico, emblemático, emocional, que é mais importante do que a perspectiva de recuperar um passado repleto do idílio do verdadeiro. Nesses fluxos emergem uma memória que permite acionar interpretações mais complexas, sobretudo quando os entrevistados possuem uma longa trajetória de vida. Trajetórias que fazem emergir nos trabalhos memoráveis uma particular relação passado/presente/futuro.

O segundo aspecto diz respeito ao modo como se realiza a escuta. Ao procurar observar atentamente gestos e expressões que expressam muitas vezes o indizível, 
fundamental na prática clínica, produzimos também o movimento de considerar os silêncios como expressão significativa do passado que chega ao presente com gestos encobridores nos fluxos de memória entre os tempos. Uma parada brusca na fala, um olhar perdido no horizonte e uma lágrima furtiva na face dos sambistas idosos eram significativos de um mundo e de um passado que causava emoção, dor, angústia, alegria ou desespero, entre tantos outros sentimentos. Observar, nesse caso, trazia mais informações e conhecimento da vida de cada um dos entrevistados, do que atentar para a construção de cenários nas respostas que forneciam nestes momentos.

\section{Considerações finais}

Ao longo deste artigo procuramos mostrar as aproximações e distanciamentos da técnica da entrevista na clínica analítica e na produção de histórias de vida. Observamos que ambas possuem pontos de encontro, cruzamentos, transversalidades, como também divergências e afastamentos.

No decorrer do texto, analisamos, brevemente, alguns procedimentos da clínica que poderiam ser adotados nas entrevistas de história de vida, de forma a construir uma abordagem que tenha como resultado um conteúdo mais aprofundado para as pesquisas. Nesse sentido, destacamos, então, três pontos que consideramos mais relevantes.

O primeiro é a realização do que poderíamos chamar de encontros de reconhecimento, em datas anteriores a da realização da entrevista, de forma que o entrevistador se inteirasse um pouco mais do cotidiano de vida dos entrevistados, produzindo minimamente um conhecimento mais profundo sobre aquele personagem. Isso é particularmente importante quando a metodologia da história de vida não está acoplada a outra ação empírica de natureza imersiva (etnografias, cartografias, etc.) que normalmente preenche essa lacuna.

Esses encontros prévios seriam importantes para a produção de vínculos com os entrevistados, fundamentais para o aparecimento de conteúdos situados, muitas vezes, em zonas de silêncio. Esse seria, então, o segundo ponto importante a ser considerado nas entrevistas de história de vida.

A terceira apropriação diz respeito ao ponto inicial da entrevista. Esta deveria começar pelas associações livres dos entrevistados e não a partir da lógica cronológica. O uso de associações livres, desprezando a rigidez da cronologia em que a vida do entrevistado se revela numa trajetória temporal linear, poderia fazer emergir aspectos mais significativos, 
identificados pelo próprio sujeito sobre sua vida, bem como conteúdos inconscientes.

Esses caminhos só puderam ser pensados a partir da percepção de que é a prática, mais do que a teoria, o que transforma alguém em analista, como defende Freud (1913). Na posição de alguém que habita esses dois espaços, de analista e de pesquisadora, pude tecer comparações entre as escutas realizadas nesses dois contextos. São quase vinte anos trabalhando com a clínica e dez de prática metodológica, utilizando as histórias de vida como objeto privilegiado de pesquisa na área de comunicação e cultura.

Assim, é possível afirmar que o que aproxima os dois universos é a vida humana. São narrativas de vidas que atravessam as duas entrevistas. E, com essas vidas, seus elementos constitutivos: memória, identidade, narrativa, escuta, silêncio, transferência, recalque, etc. São esses processos que habitam as entrevistas. Cada qual com sua particularidade, seus distanciamentos e aproximações.

As nuances de aproximação têm conexão, também, com os campos de atuação: as histórias de vida não dizem respeito às materialidades, nem estão relacionadas apenas a narrativas objetivas. Nelas, estão presentes a emoção, a subjetividade, os comportamentos. Elementos conhecidos da Psicologia e que também são, cada vez mais, matéria prima de estudos comunicacionais.

A questão de reconstrução de si talvez seja o ponto de maior conexão dessas técnicas, realizadas sempre a partir da fala. E, a partir desse ato reinaugural de si, o indivíduo, nas palavras de Pollak (1989, p.13), "tende a definir seu lugar social e suas relações com os outros". Falar de si é reconstruir identidades. Tanto a entrevista clínica como a narrativa baseada nas histórias de vida permitem ao ser humano a consciência de sua existência no mundo. 


\section{Referências}

AMADO, Janaína. A culpa nossa de cada dia: ética e história oral. Projeto História. São Paulo: v.15, abr. 1997.

AMADO, Janaína; FERREIRA, Marieta de Moraes (org.). Usos e abusos da história oral. Rio de Janeiro: Editora FGV, 2006.

AGUIAR, Maria Lívia de Sá Roriz. Cidade Jongueira: Rio de Janeiro e os territórios do jongo. 2018. Tese (Programa de Pós-Graduação em Comunicação e Cultura da Escola de Comunicação) - Centro de Filosofia e Ciências Humanas, Universidade Federal do Rio de Janeiro, Rio de Janeiro, 2018.

AGUIAR, Maria Lívia de Sá Roriz. Homens memória: a Velha Guarda e a guarda das tradições do samba carioca. 2013. Dissertação de Mestrado (Programa de Psicologia Social do Instituto de Psicologia) - Centro de Educação e Humanidades, Universidade do Estado do Rio de Janeiro, Rio de Janeiro, 2013.

CANDAU, Joël. Memória e identidade. São Paulo: Contexto, 2011.

FREUD, Sigmund. Recomendações aos médicos que exercem a psicanálise (1913). Rio de Janeiro: Imago, 1969. Edição Standard Brasileiras das Obras Psicológicas Completas de Sigmund Freud. v. XII,

FREUD, Sigmund. Repetir, recordar e elaborar (1914). Rio de Janeiro: Imago, 1969. Edição Standard Brasileiras das Obras Psicológicas Completas de Sigmund Freud. v. XII.

HALBWACHS, Maurice. A memória coletiva. São Paulo: Centauro, 2006.

HUYSSEN, Andréas. Seduzidos pela memória. Rio de Janeiro: Artiplano, 2000.

NORA, Pierre. Les lieux de mémoire. Paris: Gallimard, 1984. v. 1.

POLLAK, Michael. "Memória, esquecimento, silêncio". Estudos Históricos. Rio de Janeiro: v. 2 , n. 3, p. 3-15, 1989 .

POLLAK, Michael. "Memória e identidade social”. Estudos Históricos. Rio de Janeiro: v. 5, n.10, 200-212, 1992.

PORTELLI, Alessandro. Ensaios de história oral. São Paulo: Letra e Voz, 2010.

PORTELLI, Alessandro. Tentando aprender um pouquinho. Algumas reflexões sobre a ética na história oral. Projeto História, São Paulo, n. 15, abr. 1997.

RICOEUR, Paul. A memória, a história, o esquecimento. Campinas: UNICAMP, 2008.

Submetido em 30.09.2020

Aprovado em 09.11.2020 